\title{
Research on the Docking of Social Media and Government Information Release in Emergency Management
}

\author{
Jinlan Guo ${ }^{1, a}$ \\ ${ }^{1}$ Department of Computer Teaching, Shanghai University of Political Science and Law, China \\ a48446678@qq.com
}

Keywords: emergency management, government information release, social media, docking research.

\begin{abstract}
This paper aims to study the development of communication mode among government, the rescue workers, the public and the victims during the process of emergency management. In the environment of mobile Internet, in perspective of our government, the establishment of an emergency information system which integrates social media platform and traditional government information release platform realizes seamless docking, better services the victims, the public, and the rescuers and provides them real and effective information, so that they would better respond to the emergencies, and reduce disaster losses, as well as improve their administrative capacity and increase the public awareness of government's credibility.
\end{abstract}

\section{Introduction}

China is in a crucial period of economic transition and social transformation. The issues including its economic system, economic structure and economic growth mode of resource utilization are all obvious. The new system and the old system are crossed. The urban and rural developments are disordered. The gap between the rich and the poor is widened. The administrative function of government is inefficient. Corruption occurs sometimes. The values become increasingly complex. The urbanization rapidly increases. The population also rapidly increases. The degree of concentration gradually accelerates. However, the natural ecological environment increasingly becomes fragile. And the city's resilience is not bearable enough. When the disasters occur, how to make effective and timely communication among the involved administrative departments of our government at all levels, social relief organizations, news media, the public and the victims is worthy of study, as well as how to optimize human and material resources to relief the victims and lower the losses to a minimum level. This is more significant in the condition of modern information technology, especially the development of mobile Internet, social media, the application of various social APP (for instance, Weibo, WeChat, etc). These make the flow and exchange of information more convenient and timely. Integrating these means of communication into all stages of emergency management will greatly improve the management effectiveness.

\section{The Necessity of Social Media in Government Information Release}

In a time of crisis, social media, such as Weibo, WeChat and forums could be self-saving platforms for the victims and the public. Sometimes, the public get the information of emergency incidents from the Internet. In 2014, the proportion of China's mobile phone that accesses to the Internet is $85.8 \%$, which is higher than the proportion of PC (70.8\%) and laptops (43.2\%). It is also higher than the global average. There is no doubt that our country has been a great one of mobile Internet.

Therefore, it is of great significance for all the countries and government at all levels to effectively combine social media and traditional government information release and make better information communication while we are in crisis. 


\section{The Present Application Modes of Social Media in Government Information Release}

In recent years, the Chinese government has taken big efforts in Internet-based information exchange. For instance, a system of government information disclosure, a network spokesperson system of national government departments at all levels, and so on. The communication modes between some government departments and the public still need to be improved. This is mainly influenced by the planned economy system which causes the ideological idea of "official position” . And the government departments pat much attention to management instead of service. They also do not attach much importance to public administration. Although some government departments launch micro-channels to publish information, such as, WeChat and Weibo, they mainly use the basic functions. Actually, they are just the electronic edition of official papers and the contents are much simple.

\section{Government's Attitude Towards the Application of Social Media}

Since the rise of mobile Internet, our government at all levels has been using new technologies in management and service. In the end of 2005, the water pollution crisis occurred in Harbin. The rumors swirled in the occasion. The local government sent messages to the public several times, so that they could understand the truth and relieve their confusions. Nowadays, social media has been widely applied in some vital emergencies, such as real-time monitoring of natural disasters, large-scale search and rescue operations, etc. In terms of these incidents, social media is of great importance and its values have been gradually shown. On April 1st, 2014, a study was published in Proceedings of the National Academy of Sciences of the United States of America. The study showed that social networking alone is likely to realize social mobilization. For instance, while searching the suspect after the Boston Marathon bombings, the social network make national mobilization come true. And finally with the help of the residents, the suspect was arrested. However, the problems caused by insufficient usage of Internet social networking still exist. In 2013, Philippines' Typhoon, Haiyan, caused thousands of deaths. Before the disaster, people there did not get any warning about this typhoon and take the necessary protective measures. If the usage of social networking platforms can be improved, there may be different results.

In the current social networking environment, the common citizens have become the information provider, instead of receiver. In the past, ordinary citizens only got limited information about the disasters. But now it is different. The social networking platform between people can be a very powerful communication tool. And our government can use it to form a better coping mechanism. How to effectively collect the information published in social media (for instance, Weibo, WeChat, online forums and so on) needs to be solved. The information owned by the public can be quickly spread through personal channels. Compared to this, many emergency departments have a lot of public information which is difficult to be obtained (such as emergency resources map), and it is relatively reliable. Therefore, it requires in-depth study of how to integrate the formal and informal information to achieve the goals of emergency response. For instance, we need to increase the speed of emergency response, to rapidly integrate the public power, to enhance the public's ability to self-organize and to improve the transparency of emergency services and so on. At the same time, the information transfer mode based on two different sources and communication approaches should also be studied, as well as how to design the system to ensure its efficiency.

Network platforms also bring government much more supervision in crisis management. Some defects or wrong way to deal with the crisis might be expanded with the network, which gives government great credibility challenges. The government's previous communication mode which is stress-driven has not been suitable in the age of Internet.

\section{The Development of Information Release Model in Government's Crisis Management}

Currently, government's information release is still one-way. It mainly relies on television, newspapers and government websites. Large numbers of government departments have their own 
official accounts, such as Sina Weibo, Tencent Weibo, as well as some accounts closely related to people's life. These have attracted a lot of fans to follow. For instance, Ping'an Beijing has about 10.7 million fans, which has been a WeMedia with great influence. And due to the function of repost, the information is transmitted much faster than before. In the case of Tianjin Tanggu bombings, there is no integrated platform for information sharing among the victims, emergency command posts, fire department, medical care and other relief organizations. Figure 1 shows the current information exchange among the victims, relief organizations, government emergency response departments, volunteers and the public during the crisis, as well as the government's emergency management.

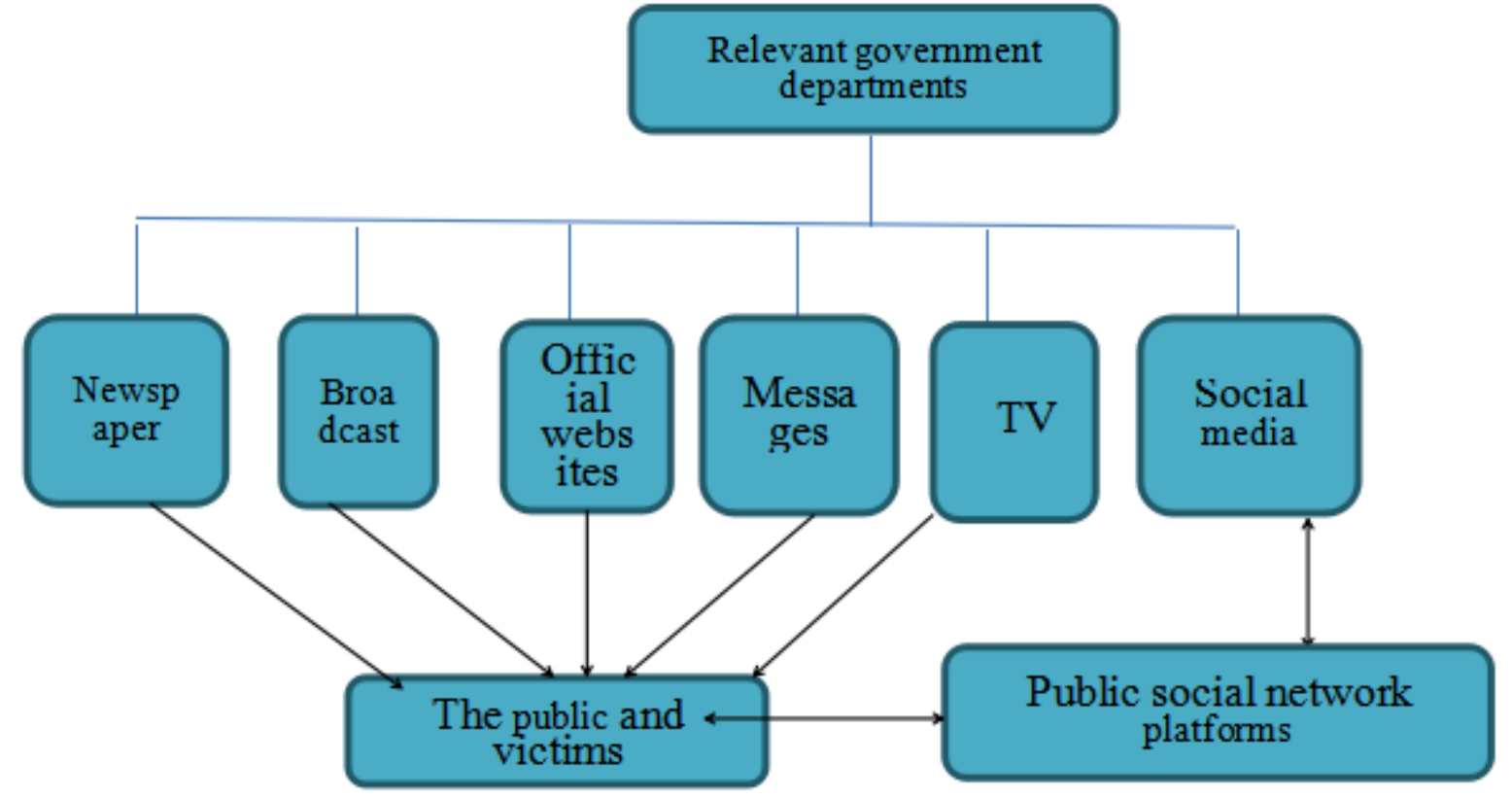

Figure 1 Present Communication Mode of Emergency Information

Governments can publish information through traditional media, such as television, newspapers, radios and government websites. It can also releases information through social media, such as Weibo, WeChat and so on. However, the relevant government departments having the social media accounts always make their papers electronic. They do not extract from social media and actively analyze the valuable information. Government policies on new media network have gradually changed. In the past, the policies always prevent its development. But now, it's much open and collaborative. The better usage, development and governance contribute to global network management. Personally, the government departments should own their public accounts of social media. In this case, the departments would be persuasive in supervision. When forced to prove themselves, it would be helpful.

When a disaster occurs, if the victims and other emergency response agencies could directly share information in the same platform, the government would rapidly release the investigation process of the crises and promptly publish the truth, which helps to keep sustained and transparent communication and to ease crisis psychosocial stress. For example, in the event of bombings happened in Tanggu District, Tianjin, government emergency response departments should promptly release the information of explosive substances, the reason causing the accident, the influences of bombings on surrounding environment and air, so that people could understand the most realistic situations. The victims could publish the first-hand information to the integrated information platform, such as pictures and videos. Since the information is checked, it can be shared to all the emergency services personnel and the masses. The on-site firefighters can also use this platform to send out live pictures and videos. The experts of dangerous goods can judge the danger and destructiveness of the goods according to this platform, which may be more effective during the relief process. The victims affected in the crisis can use this integrated information platform and know the distribution of the wounded in different hospitals and the hospitals' treatment capacity, so that they could make optimized medical treatment decisions. The volunteer organizations can learn from this platform how 
to help the victims. The integrated system of emergency information adopts social media and the government's information channels to integrate in an information system in crisis, which could be used by the people involved (Figure 2).

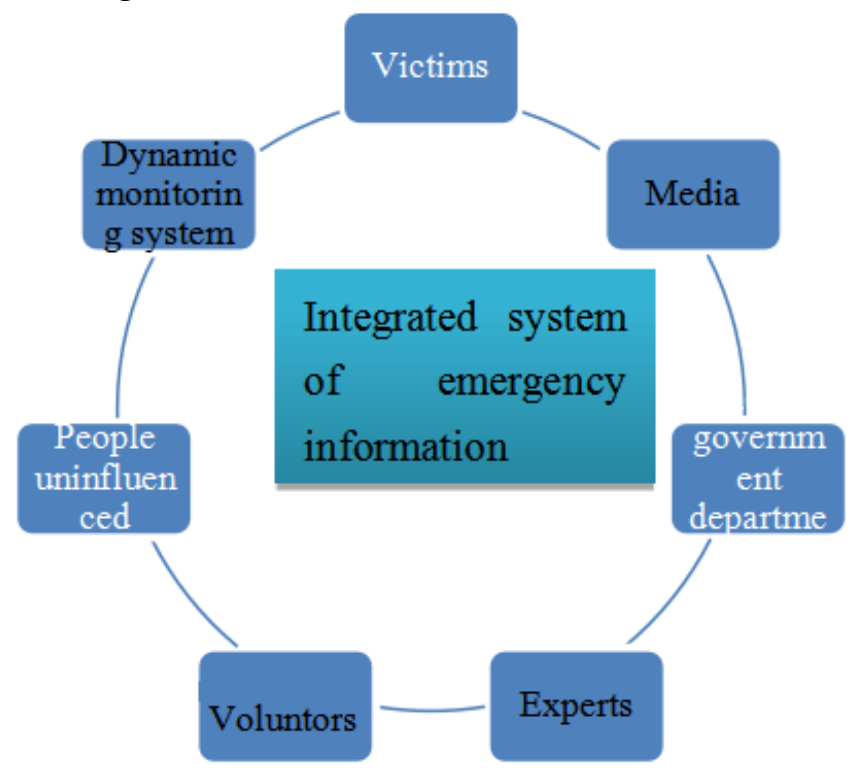

Figure 2 Communication Mode of Integrated System of Emergency Information

\section{The Integration System of Emergency Information}

In the current social networking environment, the information on disasters published in social media firstly comes from the residents who are affected in the disaster areas. For instance, the bombings occurred in Tanggu District, Tianjin. The public's latest understanding is from the online pictures shown by the local Internet users, such as videos and some damaged sites, injured people and so on. Government at all levels, however, is still reporting through press conference, television, newspaper and websites. The usage of social media is not enough. And no timely usage of social media is done to effectively transform real-time information. The integration system of emergency information integrate the information collected from government, the disaster area, the public after its reliability is verified. The information includes audio, videos and photos and so on.

In perspective of the government, the integration system of emergency establishes its information platform on basic of mobile Internet. Therefore, it could collect large of information and analyze it, as well as save and output it. On one hand, this system provides the residents with local information and emergency guidance. On the other hand, it allows the residents to use computers or mobile communication equipments, mobile phones or tablet computers, to transmit information, photos or videos. It allows the residents to report disasters, such as flash floods, tornadoes, hurricanes, public health and terrorist attacks. This system collects a large amount of data generated during the crisis, such as the terminal monitoring data and rescue information. The structured treatment is followed. The collected information would be comprehensively analyzed. And then the emergency response information would be published through the residents' phones, e-mails, or mobile equipments, such as psychological interventions and secondary disaster prevention.

If it is necessary, we can set up a dynamic monitoring system in disaster area. For instance, after the bombing occurred in Tanggu District, Tianjin, the dynamic detection systems of air, water and soil were set in some monitoring points. The data is updated every day. Through the data collection and analysis, we can dynamically report the quality of the air, water and soil there, which has a significant effect on the victims and the reconstruction. To establish a dynamic monitoring system is the main part in crisis information management. It mainly includes data collection, data display, interest records and data records. Data collection should be accurate, complete and timely. The specific contents include hazard assessment data, crisis rescue teams and rescue resources disposition, shortage degree and supply allocation, etc. Through the emergency response center and on-site scene 
display devices, the combination of rescue information and on-site coordination system contributes to provide supervisors with proper decisions and optimized collocation of different resources.

The integration system of emergency information integrates various media. After the outbreak of a crisis, social media give the real-time report at the first time, which meets the basic requirement of people's confirmation and avoid the rumors. Later, we could invite experts and scholars to discuss the crisis situation and its causes and put forward accurate measures. Based on rescue information summarized by coordination center, the victims would know the places providing food, tents and medicine care. And they could also help the volunteers to help the weak, organize other people to save themselves, so that they could correctly face the disaster. Media, as a disseminator of information, plays a vital role in guidance in people's life. Government and the media must be closely linked to mobilize all sectors of our society to participate in emergency donation and transportation, and guide people's ideas and call upon people to donate. This also contributes to make the emergency supplies and qualified pharmaceuticals flow to the emergency logistics center; as well as guide the people with right response and participation in rescue.

\section{Conclusions}

The integration system of emergency information is mainly responsible to share the information to the involved departments and people after a disaster occurs. It not only includes the government's information release in crisis in the state of release, but also the collection of people's response to the crisis. The integration system of emergency information should play a role in warning, conveying emergency information, guiding people to participant in rescue, supervising and evaluating and some other social information service, which helps to form a virtuous information diffusion mechanism of crisis management.

\section{References}

[1] WU Jianmin. The Functions of Social Media in Government [J]. GOUFANG ZHINAN, 2011, 08.

[2] XU Wencai. Research on Portal Emergency Management Service of Our Provincial Government [C], 2013.

[3] LV Xiaoli. Information and Communication of Government Emergency Management in the Era of web2.0 [J]. NATURAL DISASTER REDUCTION IN CHINA, 2010, 05.

[4] FENG Yan. Research on Government Information Disclosure in Sudden Natural Disaster Emergency Management [C]. 2009, 12: 1.

[5] KUANG Qiyu. The Functions of Social Media in Catastrophe Risk Management [C]. 2014.

[6] XU Jing. Use of Social Media for Governmental Risk and Crisis Communication [J]. Social Sciences in Nanjing, 2013, 05. 